\title{
Histology and Ultrastructure of a Tissue-Engineered Collagen Meniscus Before and After Implantation
}

\author{
Marcella Reguzzoni, ${ }^{1}$ Alessandro Manelli, ${ }^{1}$ Mario Ronga, ${ }^{2}$ Mario Raspanti, ${ }^{1}$ Federico A. Grassi ${ }^{2}$ \\ ${ }^{1}$ Department of Human Morphology, University of Insubria, Varese, Italy \\ ${ }^{2}$ Department of Orthopaedics and Traumatology, University of Insubria, Varese, Italy
}

Received 6 June 2004; revised 3 February 2005; accepted 7 February 2005

Published online 24 June 2005 in Wiley InterScience (www.interscience.wiley.com). DOI: 10.1002/jbm.b.30314

\begin{abstract}
The collagen meniscus implant (CMI) is a tissue-engineering technique designed to stimulate regeneration of meniscus-like tissue in cases of irreparable tears or previous meniscectomy. CMI morphology was investigated before and after implantation by light microscopy, scanning electron microscopy (SEM), and transmission electron microscopy (TEM). In a case series biopsy specimens were harvested from four patients who underwent a second arthroscopic look 6 months after placement of the CMI. CMI sections appeared composed of parallel connective laminae of 10-30 $\mu \mathrm{m}$, connected by smaller bundles (5-10 $\mu \mathrm{m})$. This connective network formed lacunae with diameters between 40 and $60 \mu \mathrm{m}$. At greater magnification, the walls of the lacunae demonstrated tightly packed and randomly distributed collagen fibrils, with diameters ranging from 73 to $439 \mathrm{~nm}$. In the biopsy specimens, the lacunae were filled with connective tissue that contained newly formed vessels and fibroblast-like cells, presenting an abundant rough endoplasmic reticulum and several mitochondria. In the extracellular matrix, the collagen fibrils showed uniform diameters (126 $\mathrm{nm} \pm 32 \mathrm{~nm}$ ). The original structure of CMI was still recognizable, and no inflammatory cells were detected within the implant. The morphological findings of this case series demonstrate that CMI provides a three-dimensional scaffold suitable for colonization by precursor cells and vessels and leading to the formation of a fully functional tissue. () 2005 Wiley Periodicals, Inc. J Biomed Mater Res Part B: Appl Biomater 74B: 808-816, 2005
\end{abstract}

Keywords: collagen; scaffolds; porous; extracellular matrix; tissue engineering

\section{INTRODUCTION}

Degenerative joint changes may often follow meniscectomy and many patients complain of knee pain after this procedure. ${ }^{1-6}$ Different open and arthroscopic techniques have thus been described for repairing meniscal tears. ${ }^{7-10}$ However, some lesions are difficult to treat because of their location and shape, and also because tissue quality might not permit a stable repair, as in degenerative lesion. Meniscus allografts can be useful for total meniscectomies, but this invasive procedure is technically demanding and carries potential risks of transmissible diseases. ${ }^{11}$

The collagen meniscus implant (CMI) (ReGen Biologics, Inc., Franklin Lakes, NJ) is a tissue-engineering technique, described in 1992, designed for stimulating regeneration of meniscus-like tissue. ${ }^{12}$ This method has been adopted for patients who underwent partial meniscectomy or presented with irreparable meniscus tears. ${ }^{13-16}$

Correspondence to: M. Ronga (e-mail: mario.ronga@uninsubria.it) (C) 2005 Wiley Periodicals, Inc.
CMI is composed of Type I collagen derived from bovine Achilles tendon and enriched with glycosaminoglycans (GAGs), including chondroitin sulfate and hyaluronic acid, in order to stimulate cellular ingrowth. It is processed chemically and physically to remove molecular antigens and noncollagenous materials. ${ }^{15,17}$ The shape is similar to the human meniscus and the materials used are biocompatible (Figure 1)..$^{13-16}$

Preliminary clinical results showed a significant improvement of symptoms in eight of eight treated patients with a follow-up of about 6 years. ${ }^{13,14}$ Human biopsy specimens harvested 1 year after implantation showed cellular colonization and tissue ingrowth within the scaffold. Light microscopy observations demonstrated newly formed fibrocartilage with dense, well-organized collagen bundles. ${ }^{13,14,16}$

However, there are no published ultrastructural data regarding CMI before and after implantation in humans. In the present case series the objective was to report pre- and postoperative findings observed by light microscopy, scanning electron microscopy (SEM), and transmission electron microscopy (TEM). It was hypothesized that the newly formed tissue would have morphological characteristic similar to native meniscus tissue. 


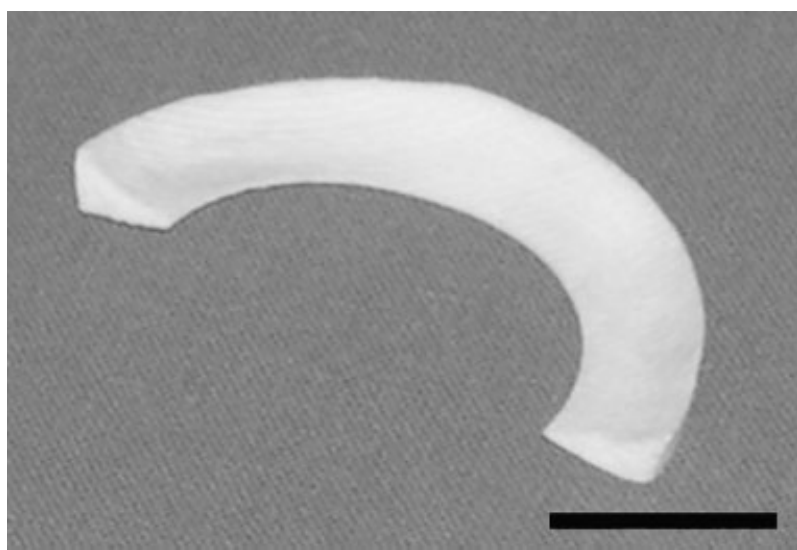

Figure 1. Collagen meniscus implant (CMI). The semicircular shape and triangular section are similar to the human meniscus (Bar = $15 \mathrm{~mm})$.

\section{MATERIALS AND METHODS}

CMI was performed on four patients, affected by traumatic irreparable tears of the posterior horn of the medial meniscus. All the procedures were carried out arthroscopically according to the surgical technique described by Rodkey and coworkers (Figure 2). ${ }^{13,16}$ Patients' ages ranged from 24 to 50 years, with an average of 38 years. The meniscus tear was the sole intrarticular lesion detected, and the chondral surfaces of the medial compartment were intact.

CMI samples were collected at the time of surgery from residual portions of the scaffolds implanted in these patients. Biopsy specimens were harvested 6 months after implantation from the same patients, at the time of a second arthroscopic look, performed for evaluating the implant evolution. No patients complained of pain or other symptoms in the operated knee. Written informed consent was obtained for performing both arthroscopy and biopsy.

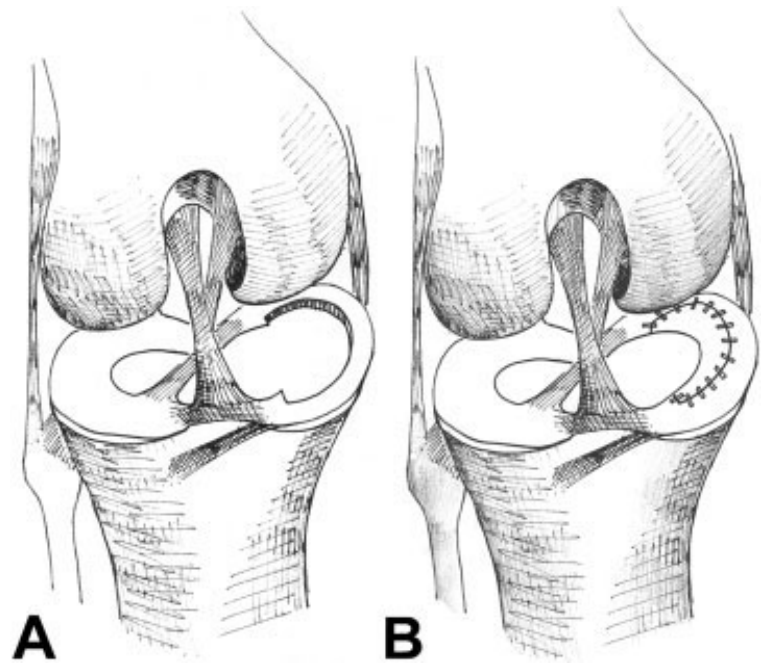

Figure 2. Diagram of CMI procedure. (A) Partial medial meniscectomy with preservation of the peripheral portion. (B) CMI suture to the meniscal stump.
TABLE I. The Lysholm Score and Tegner Activity Scale Increased in all Operated Knees During the 6-Month Period Following CMI

\begin{tabular}{|c|c|c|c|c|c|}
\hline \multirow[b]{2}{*}{$\begin{array}{l}\text { Patient } \\
\text { Number }\end{array}$} & \multirow[b]{2}{*}{$\begin{array}{l}\text { Age at } \\
\text { Index } \\
\text { Surgery }\end{array}$} & \multicolumn{2}{|c|}{ Before Surgery } & \multicolumn{2}{|c|}{$\begin{array}{l}6 \text { Months after } \\
\text { Surgery }\end{array}$} \\
\hline & & $\begin{array}{l}\text { Lysholm } \\
\text { Scale }\end{array}$ & $\begin{array}{c}\text { Tegner } \\
\text { Activity } \\
\text { Scale }\end{array}$ & $\begin{array}{l}\text { Lysholm } \\
\text { Scale }\end{array}$ & $\begin{array}{c}\text { Tegner } \\
\text { Activity } \\
\text { Scale }\end{array}$ \\
\hline 1 & 24 & 70 & 3 & 100 & 5 \\
\hline 2 & 36 & 68 & 2 & 95 & 5 \\
\hline 3 & 42 & 70 & 2 & 98 & 4 \\
\hline 4 & 50 & 41 & 2 & 82 & 4 \\
\hline Mean & 38 & 62.25 & 2.25 & 93.75 & 4.5 \\
\hline
\end{tabular}

All knees were evaluated before CMI and at the time of biopsy with the use of the Lysholm II score and Tegner activity scale. The biopsies were performed with an $18 \mathrm{G}$ Temno device (Allegiance Healthcare Corp., McGaw Park, IL), routinely used for prostate biopsies. This device minimized trauma to the implant-new tissue complex. Biopsy specimens measured $8 \mathrm{~mm}$ in length and $0.7 \mathrm{~mm}$ in diameter.

All samples were immediately fixed in $2.5 \%$ paraformaldehyde and $2 \%$ glutaraldehyde in $0.1 \mathrm{M}$ Na-cacodylate buffer $\left(\mathrm{pH}\right.$ 7.4) for $6 \mathrm{~h}$ at $4^{\circ} \mathrm{C}$. Subsequently, they were subdivided in three different groups.

Light Microscopy. Specimens were dehydrated in ascending grades of ethanol and then embedded in paraffin. They were sectioned at a 5- $\mu \mathrm{m}$ thickness with a Reichert Ultracut S ultratome (Leica, Vienna, Austria) and then stained with hematoxylin and eosin. Histological evaluation was performed with light microscopy (Nikon Eclipse E600 microscope, Nikon, Tokyo, Japan).

Scanning Electron Microscopy. Specimens were postfixed in a solution of $1 \%$ osmium tetroxide and $1.5 \%$ potassium ferrocyanide for $3 \mathrm{~h}$. Slices were washed in $\mathrm{pH} 7.2$ phosphate-buffered saline (PBS), dehydrated in ascending grades of ethanol and subjected to critical-point drying in $\mathrm{CO}_{2}$. Dried slices were mounted on standard stubs, goldcoated in an Emitech K550 sputter coater (Emitech Products Inc., Houston, TX) and then observed on a Philips XL-30 SEM-FEG microscope (FEI, Eindhoven, Netherlands) fitted with a $1424 \times 968$ pixel frame store for direct digital imaging. Collagen fibril diameters before and after implantation were compared by measuring 1000 fibrils on 40 SEM images. The diameter of collagen fibrils was determined by a digital ruler (AnalySIS, Soft Imaging System, Munster, Germany) and divided into 25 diameter classes, each corresponding to a 14-nm interval.

Transmission Electron Microscopy. Specimens were postfixed for $2 \mathrm{~h}$ with $1 \%$ osmium tetroxide in $0.1 \mathrm{M} \mathrm{Na}$ cacodylate buffer $(\mathrm{pH} 7.2)$ at $4^{\circ} \mathrm{C}$. After standard dehydration 


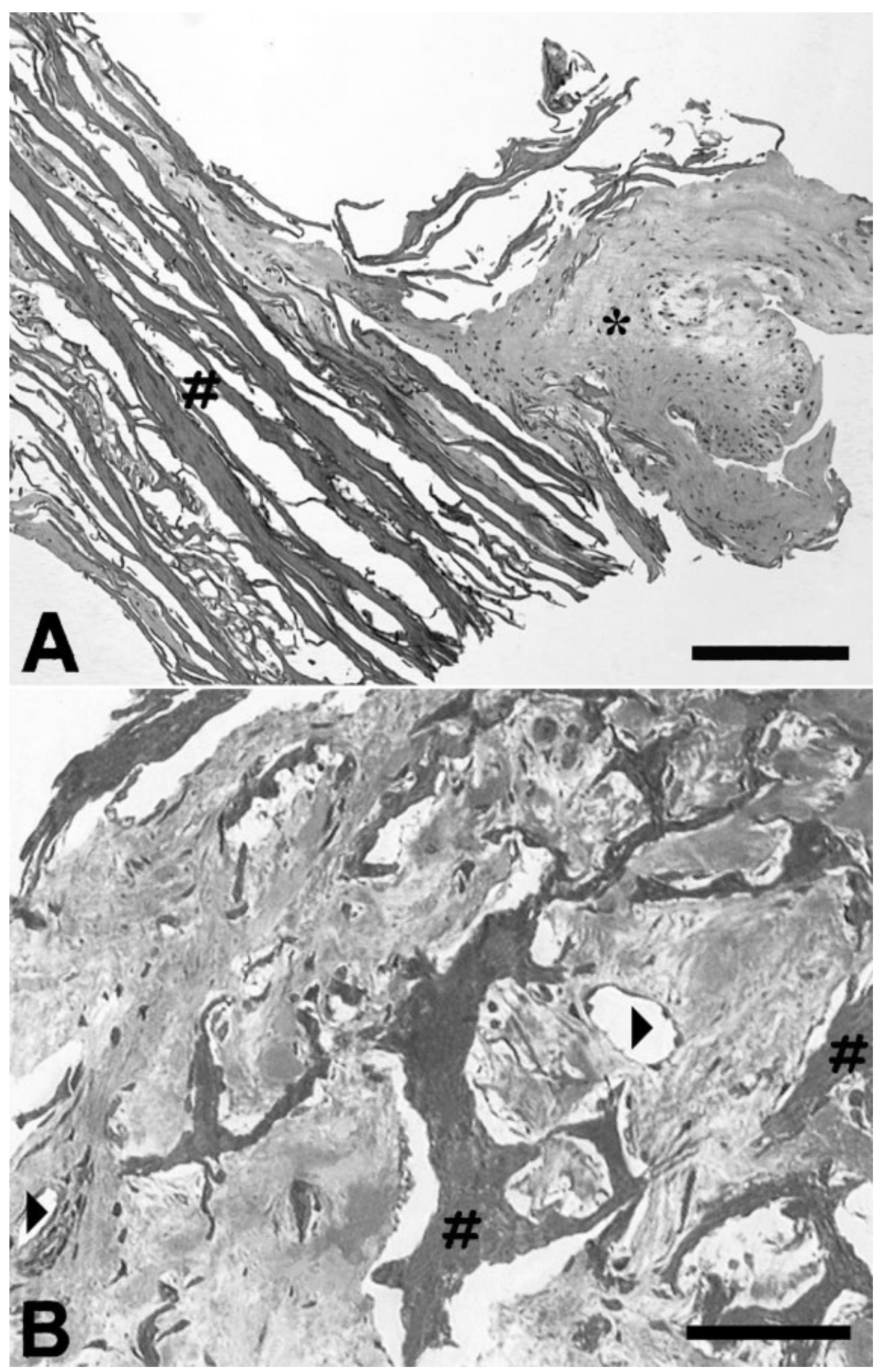

Figure 3. Light microscopy of the implant stained with hematoxylin and eosin. (A) The CMI (number sign) is partially invaded from posterior meniscus tissue (asterisk). A more compact scaffold is evident (bar $=500 \mu \mathrm{m})$. (B) The CMl scaffold is clearly evident (number sign). Connective tissue inside the lacunae and new vessels (triangles) are evident (bar $=40 \mu \mathrm{m})$.

in ethanol series, specimens were embedded in Epon 812. They were sectioned to 60-nm-thick ultrathin sections with an ultramicrotome (RMC MTXL ultramicrotome, Boeckeler Instruments, Tucson, AZ) fitted with a diamond knife.
The ultrathin sections were collected on copper grids, stained with uranyl citrate and lead acetate, and observed with TEM (1010 EX electron microscope, Jeol, Tokyo, Japan). 

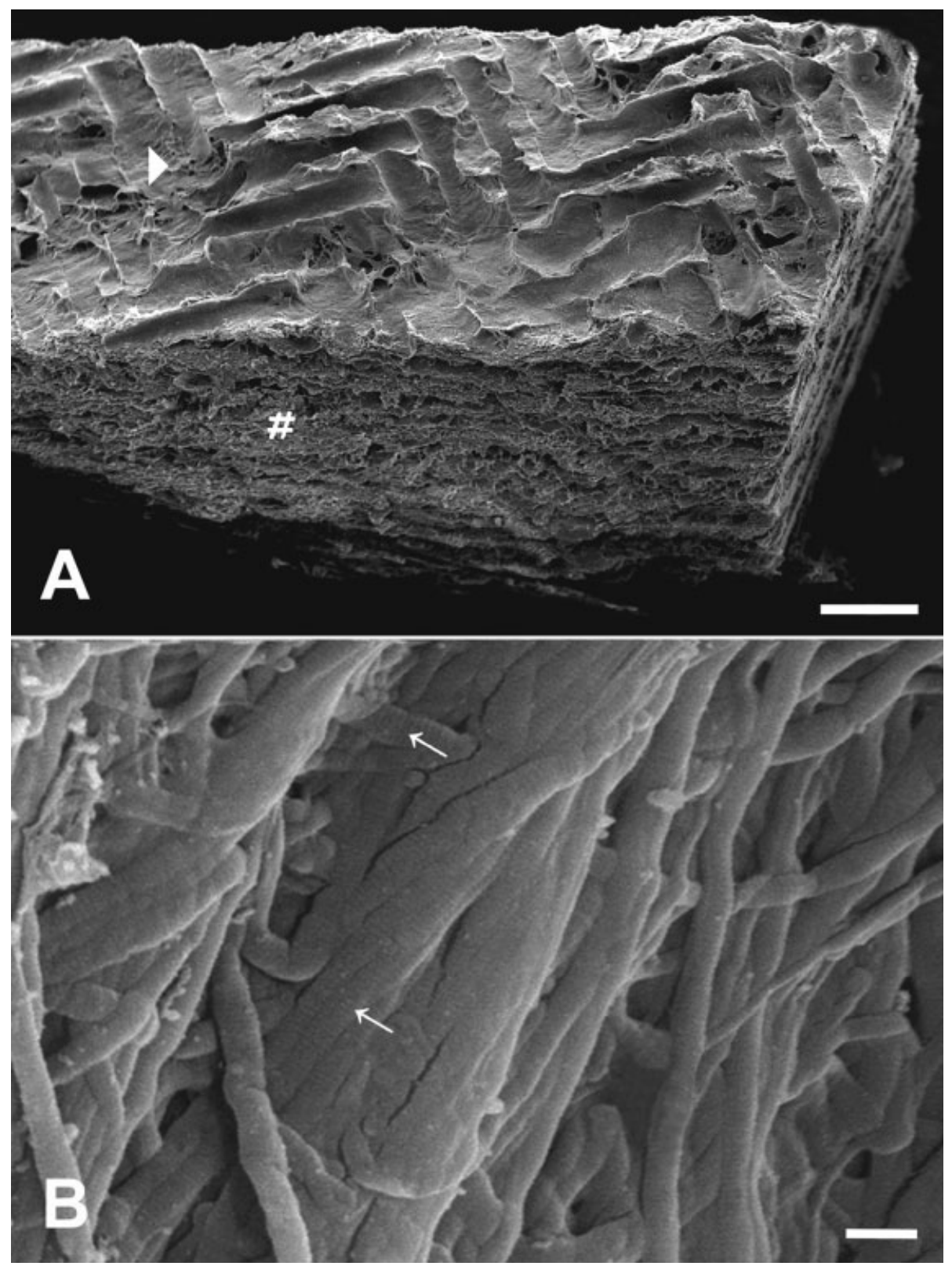

Figure 4. Scanning electron microscopy of the CMI. (A) On the top surface (triangle) some regular cristae are interposed with herringbone grooves that are about $70 \mu \mathrm{m}$ wide. The lateral surface (number sign) shows lacunae 60-90 $\mu \mathrm{m}$ wide, formed by collagen laminae interconnected by thinner fibrils (bar $=250 \mu \mathrm{m}$ ). (B) The fibrils of the lacunae wall exhibit a random distribution with diameters varying from 73 to $439 \mu \mathrm{m}$. A 67-nm period (arrows) can be observed (bar $=700 \mathrm{~nm}$ ).

\section{RESULTS}

\section{Clinical and Arthroscopic Observation}

No complications occurred in the postoperative period. All patients returned to activities of daily living by 3 months and were fully active at 6 months. The Lysholm score and Tegner activity scale increased in all operated knees during the 6-month period following CMI (Table I).

At second arthroscopic look, regeneration of meniscal-like tissue with healing of the implant to the capsule and to the residual meniscal stump was observed in all knees. Only one implant showed a small area of fragmentation that did not required any debridement. There were no signs of synovitis or joint damage, with intact chondral surfaces of the medial compartment.

\section{Light Microscopy}

Six months after implantation, the multilamellar structure typical of CMI is less evident owing to tissue invasion inside the lacunae. The more dense appearance of the implant might also result from mechanical compaction caused by compressive forces acting on the knee joint 


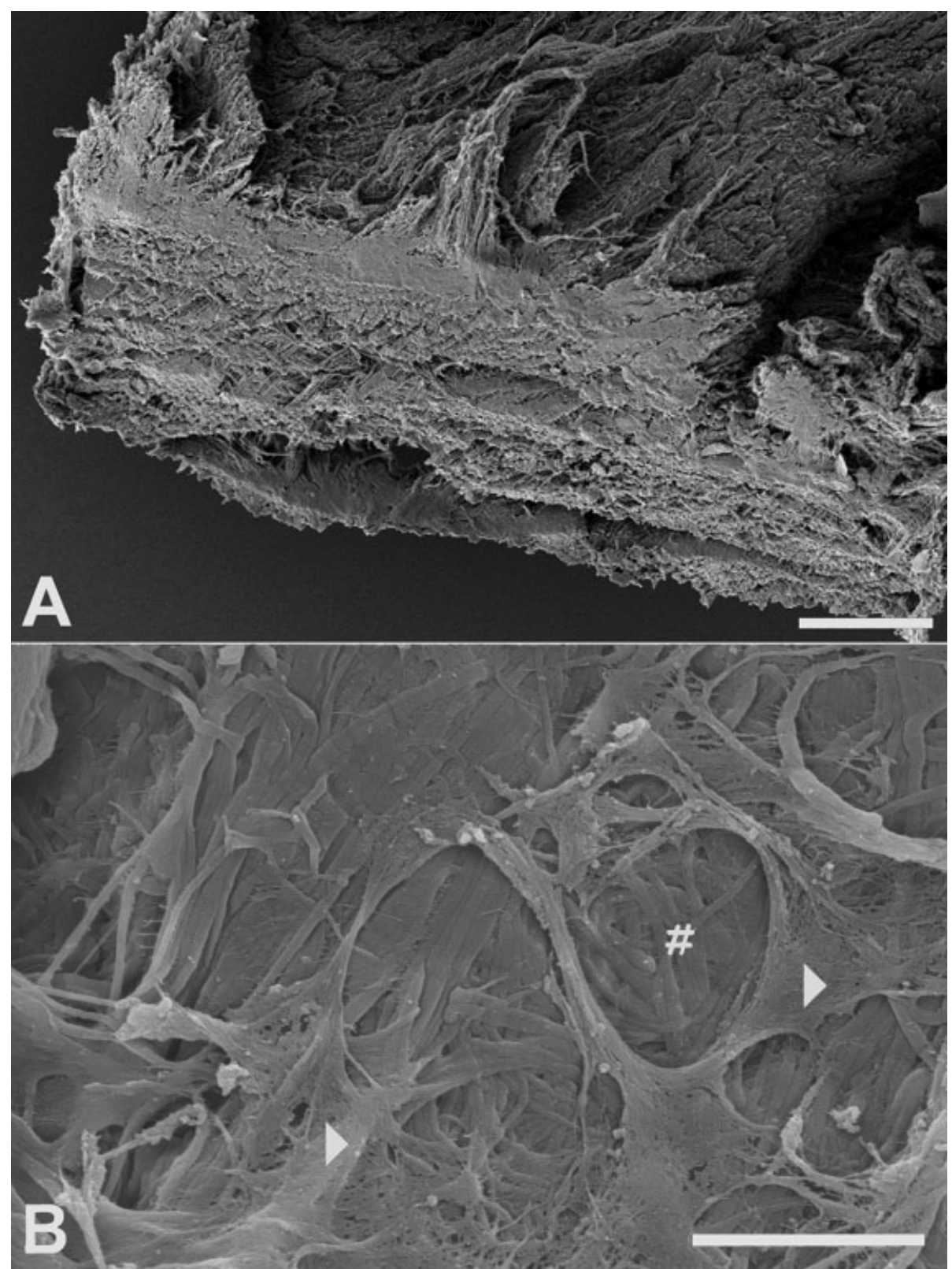

Figure 5. Scanning electron microscopy of the implant. (A) The multilamellar structure of CMI scaffold is readily recognizable $(\mathrm{bar}=100 \mu \mathrm{m})$. B) The new collagen fibrils (arrows) are readily recognizable by their small diameter in contrast with the larger and flattened fibrils of the scaffold (number sign) (bar $=5 \mu \mathrm{m})$.

[Figure 3(A)]. The architecture of the implanted CMI was preserved and the scaffold was still well recognizable, in contrast with previous in vivo studies reporting extensive scaffold resorption at 6 weeks in pigs. ${ }^{18}$ The lacunae were filled by connective tissue, where many cells, either spindle-shaped or roundish, were surrounded by newly formed extracellular matrix and blood vessels [Figure 3(B)]. No phagocytes or macrophages were observed.

\section{Scanning Electron Microscopy}

The CMI is a semicircular scaffold in which three surfaces are recognizable: upper, lower, and lateral. The upper and lower surfaces appeared composed of dense connective tissue in which cristae and grooves could be observed. The cristae were $500 \mu \mathrm{m}$ long and appeared in a herringbone

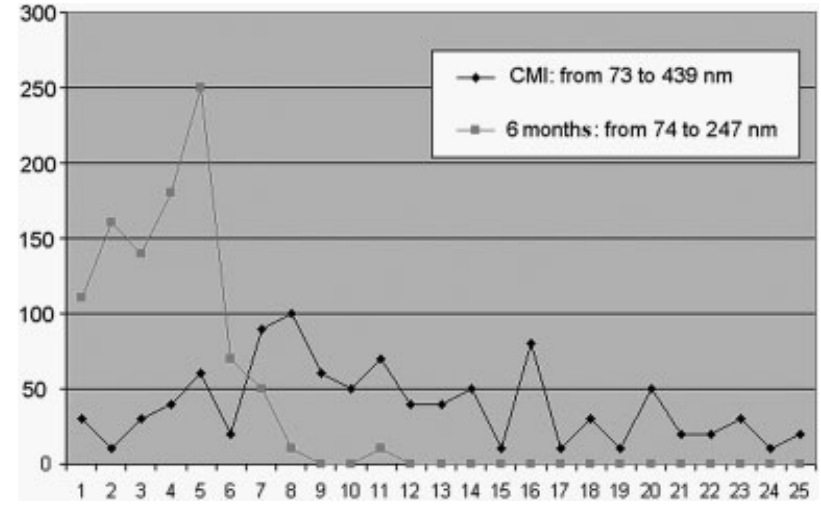

Figure 6. The scaffold fibrils show a multimodal distribution with diameters ranging from 73 to $439 \mathrm{~nm}$ (mean, $234 \pm 89 \mathrm{~nm}$ ). The newly synthesized fibrils demonstrate a broad distribution with diameters between 74 and $247 \mathrm{~nm}$ with a mean of $126 \pm 32 \mathrm{~nm}$. 

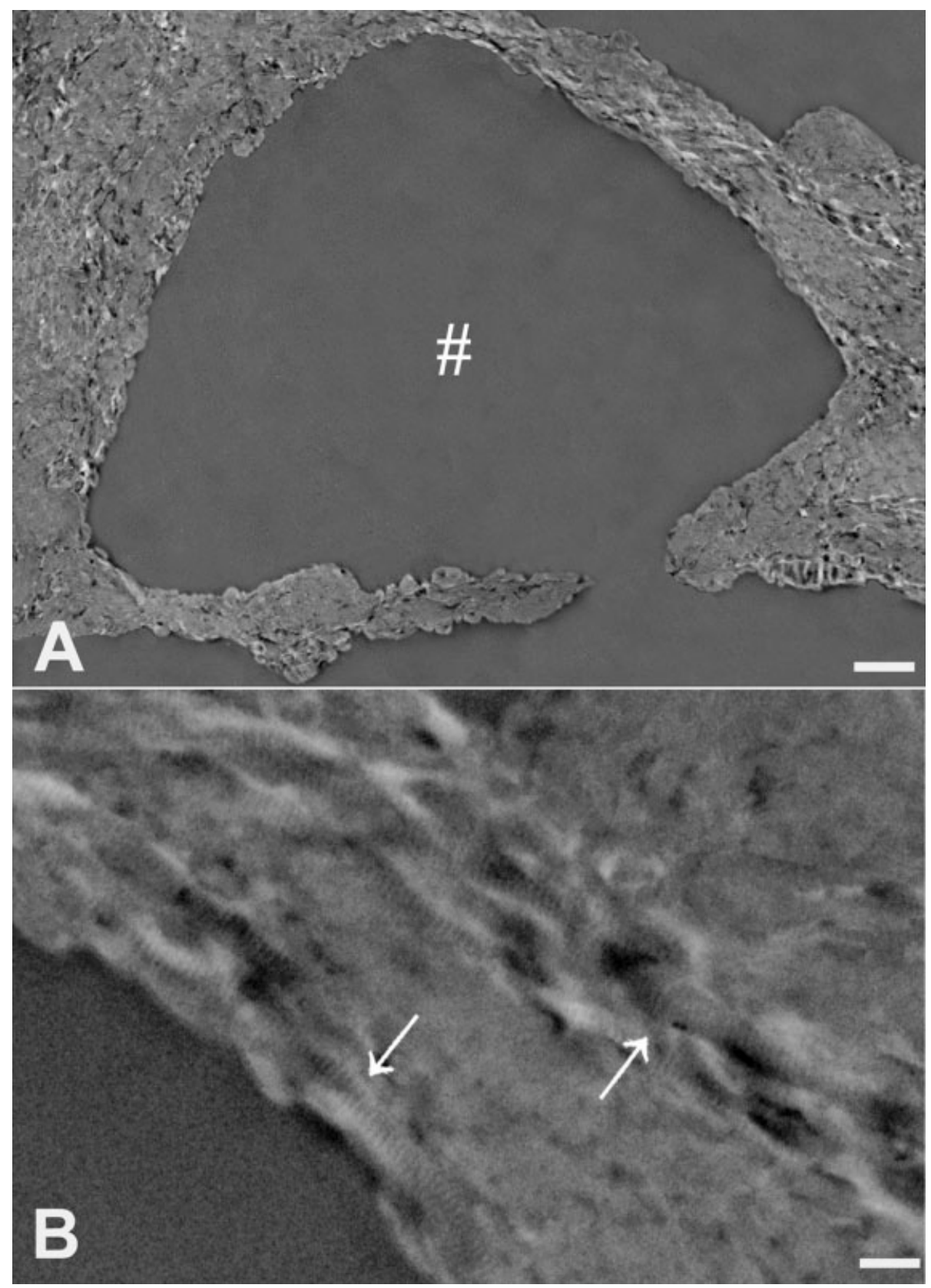

Figure 7. Transmission electron microscopy of the CMI. (A) Empty scaffold lacunae (number sign) are formed by collagen walls (bar $=2 \mu \mathrm{m}$ ). (B) Collagen fibrils are tightly packed and difficult to resolve with this technique. Their 67-nm period (arrows) is, however, evident (bar $=500 \mathrm{~nm}$ ).

pattern with $80-\mu \mathrm{m}$ wide grooves [Figure $4(\mathrm{~A})$ ]. The lateral surface of CMI contained lacunae, with diameters from 60 to $90 \mu \mathrm{m}$. The lacunae were formed by stratified connective layers in which smaller $(5-10 \mu \mathrm{m})$ connective bundles could be recognized [Figure 4(A)]. At higher magnification, the walls of the lacunae appeared composed of a randomly arranged fibrillar network. The fibrils were tightly packed and their diameters varied from 73 to 439 $\mathrm{nm}$. The collagen fibrils presented the typical $67-\mathrm{nm}$ period [Figure 4(B)].

In the biopsy specimens, the multilamellar structure of CMI was still evident, even though the lacunae were less recognizable in comparison with the preoperative samples [Figure 5(A)]. The native connective network of the scaffold was clearly distinguishable from the newly synthesized fibrils, owing to the larger and less uniform diameters [Figure 5(B)].

Based upon measurements performed at SEM, the scaffold fibrils showed a great variability in diameter, ranging from 73 to $439 \mathrm{~nm}$ (mean, $234 \pm 89 \mathrm{~nm}$ ), with a multimodal distribution. Conversely, the newly synthesized fibrils showed a broad distribution with diameters ranging from 74 to $247 \mathrm{~nm}$ with a mean of $126 \pm 32 \mathrm{~nm}$ (Figure 6). 

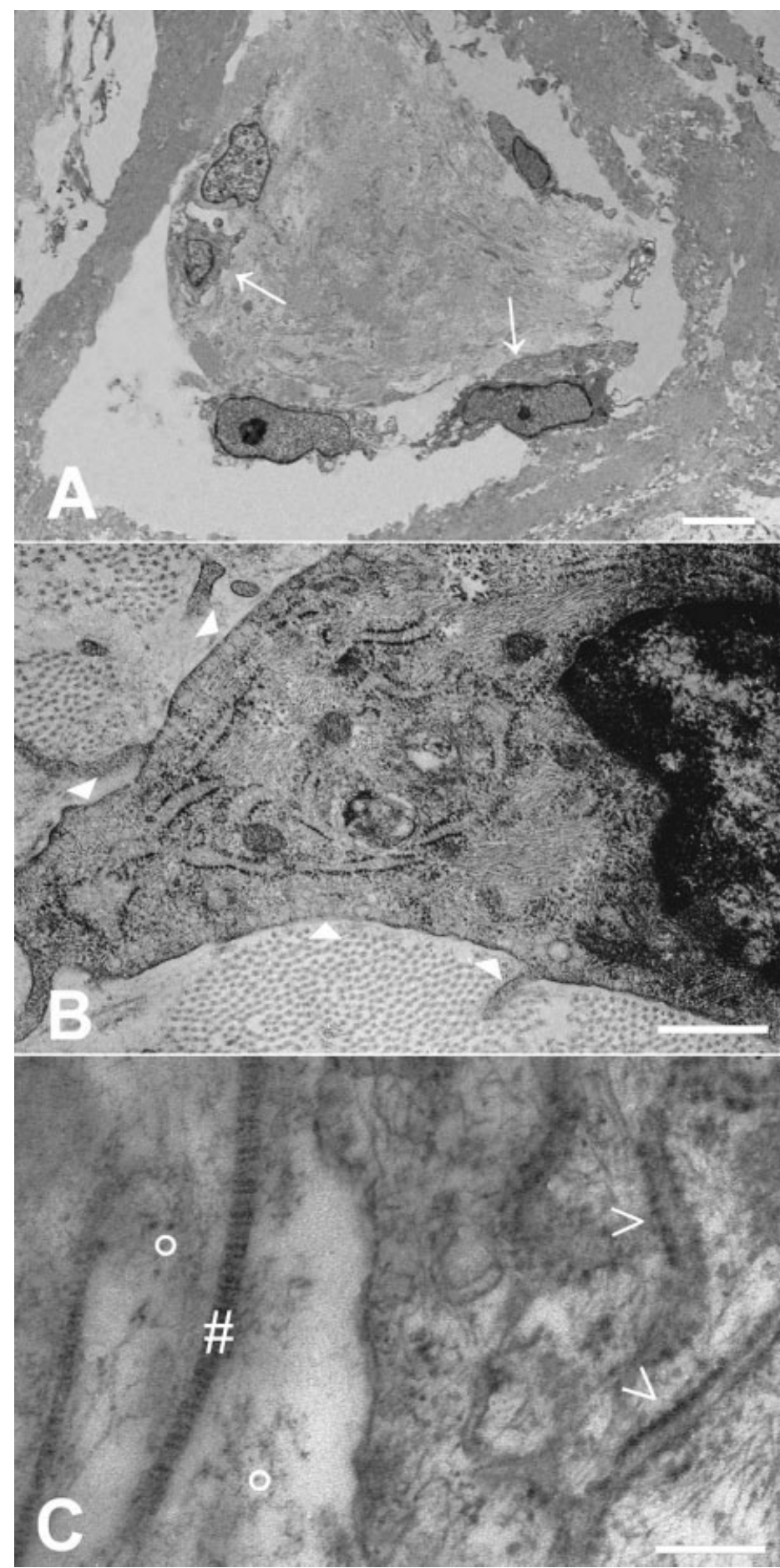

Figure 8. Transmission electron microscopy of the implant. (A) Several fibroblast like cells (arrows) with euchromatic nucleus are present within the lacunae $(\mathrm{bar}=5 \mu \mathrm{m})$. (B) The cellular cytoplasm shows rough endoplasmic reticulum, mitochondria, cisternae, and abundant vesicles. Near the cell wall some vesicles (triangles) are pouring out proteins into the extracellular matrix. The matrix is composed of parallel fibrils of regular diameters (bar $=450 \mathrm{~nm}$ ). (C) Rough endoplasmic reticulum is noted in the cell cytoplasm (pointers) Evident in the extracellular matrix is the typical $67-\mathrm{nm}$ period of collagen fibrils (number sign) The matrix adjacent to the collagen fibrils appears composed of irregular filamentous material (circles) (bar $=200 \mathrm{~nm}$ ).

\section{Transmission Electron Microscopy}

In the scaffold, no cells or cellular debris were evident inside the lacunae [Figure 7(A)]. The walls of the lacunae appeared composed of amorphous material, in which the typical 67-nm period of collagen fibrils was often recognizable [Figure 7(B)]. After implantation, the lacunae were filled by fibroblast-like cells, presenting large nuclei with a poorly con- 
densed nuclear chromatin. The cells were surrounded by new collagen matrix that was separated from the native scaffold by an empty space [Figure $8(\mathrm{~A})$ ]. An abundant rough endoplasmic reticulum, several mitochondria, cisternae, and numerous vesicles were present inside the cytoplasm. Most of the vesicles were adjacent to the cytoplasmic membrane; some of them were pouring out their contents into the extracellular space [Figure 8(B)]. Pseudopodia were also evident, showing a close relationship with collagen bundles. Similar to the SEM observation, the newly synthesized fibrils presented uniform diameters [Figure 8(B)]. At higher magnification, filamentous material was visible between collagen fibrils [Figure $8(\mathrm{C})$ ].

\section{DISCUSSION}

The collagen meniscus implant is composed of a three-dimensional collagen network, derived from bovine Achilles tendons and processed to achieve adequate biocompatibility and shape for human implantation. ${ }^{13-17}$ In accordance with previous studies, no adverse events occurred in this series of patients after CMI. A general improvement in the clinical status was observed postoperatively, but this trend might also be related to partial meniscectomy and not only to CMI. However, a recent report highlighted the effectiveness of CMI in controlling knee pain with respect to simple meniscectomy. ${ }^{14}$ Even though the followup is too short for demonstrating a chondroprotective role of CMI, there was no damage to the opposing cartilage surfaces 6 months after implantation.

On light microscopy, the CMI has lacunae formed by large, parallel connective laminae that are connected by smaller fibers. ${ }^{13,15-17}$ This structure is very similar to the in vivo conditions, and matrix synthesis can be enhanced by a porous scaffold. Indeed, research has been mainly directed to the production of porous meniscus scaffolds, derived not only from collagen, ${ }^{12-17,19}$ but also from synthetics, such as polyurethanes. $^{20-23}$

The present findings on biopsies, performed 6 months after CMI implantation, are consistent with light-microscopy observations of other authors. ${ }^{13,15,16}$ The connective framework of the scaffold is still evident in the biopsy specimens. The invasion of the lacunae by vessels, fibroblast-like cells and connective tissue matrix, as well as the absence of phagocytes and macrophages confirm the biocompatibility of CMI material.

The dense upper and lower surfaces of the scaffold, with their herringbone cristae, are clearly evident at SEM. Such arrangement, created by the manufacturing process, ${ }^{15,17}$ offers sufficient mechanical strength to resist compressive and shear stresses, and prevents cell migration outside the scaffold in contrast with the porous, multilamellar structure of the lateral surface and inner transverse sections that are designed for tissue invasion.

The collagen network of the scaffold is composed of fibrils of variable diameters. This broad distribution is actually quite distinctive for tendons and has been reported in a range of different animals, ${ }^{24,25}$ whereas the newly synthesized collagen fibrils observed in the 6-month biopsies have more uniform diameters and show a tendency to organize in bundles. This pattern resembles the normal meniscus ultrastructure, ${ }^{26}$ even though the dimensions of the biopsies do not allow us to draw conclusions about the general architecture of the collagen network.

TEM observation allowed a more detailed study of tissue ingrowth inside the lacunae. The cells show an intense metabolic activity, demonstrated by the poorly condensed nuclear chromatin, the cytoplasmic organuli, and the exocytosis vesicles. The pseudopodia organize the bundles of collagen fibrils in a three-dimensional network. ${ }^{27}$ These features, as well as the elongated shape, are characteristic of fibroblastlike cells. ${ }^{28}$ Nonetheless, these precursor cells are of unknown origin. Other authors ${ }^{12,14,16}$ speculate that the cells come primarily from the synovium, but currently no definitive data are available to confirm the cell source.

The pericellular filamentous material, the mesh-like pattern of the fibrillar network, the presence of fibroblast-like cells, and the lack of organization in chondrones demonstrate that the tissue is still undergoing a maturation process.

\section{CONCLUSIONS}

CMI is a tissue-engineering technique designed to prevent degenerative joint changes caused by meniscectomy. Morphological findings of this case series demonstrate that the collagen scaffold is still evident 6 months after implantation and does not elicit any inflammatory reaction. Histological and ultrastructural evidence of tissue ingrowth support the hypothesis that CMI possesses tissue-conductive properties for regeneration of meniscus-like tissue. The short followup of these four patients does not allow us to confirm its clinical effectiveness in the long term to prevent osteoarthritis. Further morphological studies designed to clarify the final evolution of these implants are now under way.

\section{REFERENCES}

1. Huckell JR. Is meniscectomy a benign procedure? A long-term follow-up study. Can J Surg 1965;8:254-260.

2. Tapper EM, Hoover NW. Late results after meniscectomy. J Bone Joint Surg Am 1969;51:517-526.

3. Johnson RJ, Kettelkamp DB, Clark W, Leaverton P. Factors effecting late results after meniscectomy. J Bone Joint Surg Am 1974;56:719-729.

4. Krause WR, Pope MH, Johnson RJ, Wilder DG. Mechanical changes in the knee after meniscectomy. J Bone Joint Surg Am 1976;58:599-604.

5. Northmore-Ball MD, Dandy DJ. Long-term results of arthroscopic partial meniscectomy. Clin Orthop 1982;167:34-42.

6. Veth RP. Clinical significance of knee joint changes after meniscectomy. Clin Orthop 1985;198:56-60.

7. Annandale T. An operation for displaced semilunar cartilage. $\mathrm{Br}$ Med J 1885;1:779. 
8. Ikeuchi H. Surgery under arthroscopic control. In: Proceedings of the Societe Internationale d'Arthroscopie. Rheumatology 1975;57-62.

9. Henning CE. Arthroscopic repair of meniscus tears. Orthopedics 1983;6:1130-1132.

10. Jakob RP, Staubli HU, Zuber K, Esser M. The arthroscopicmeniscal repair: Techniques and clinical experience. Am J Sports Med 1988;16:137-142.

11. Kuhn JE, Wojtys EM. Allograft meniscus transplantation. Clin Sports Med 1996;15:537-546.

12. Stone KR, Rodkey WG, Webber RI, McKinney L, Steadman JR. Meniscal regeneration with copolymeric collagen scaffolds. In vitro and in vivo studies evaluated clinically, histologically, and biochemically. Am J Sports Med 1992;20:104-111.

13. Rodkey WG, Steadman JR, Li ST. A clinical study of collagen meniscus implants to restore the injured meniscus. Clin Orthop 1999;367(Suppl.):S281-292.

14. Steadman JR, Rodkey WG. Tissue-engineered collagen meniscus implants: 5 to 6-year feasibility study results. Arthroscopy. Forthcoming.

15. Stone KR, Steadman JR, Rodkey WG, Li ST. Regeneration of meniscal cartilage with use of a collagen scaffold: Analysis of preliminary data. J Bone Joint Surg Am 1997;79:1770-1777.

16. Rodkey WG, Steadman JR, Li ST. Collagen scaffolds: A new method to preserve and restore the severely injured meniscus. Sports Med Arthrosc 1999;7:63-73.

17. Li ST, Rodkey WG, Yuen D, Hansen P, Steadman JR. Type I collagen-based template for meniscus regeneration. In: Lewandrowski KU, Wise DL, Trantolo DJ, Gresser JD, Yaszemski MJ, Altobelli DE, Editors. Tissue engineering and biodegradable equivalents. Scientific and clinical applications. New York: Marcel Dekker: 2002. p 237-266.
18. Stone KR, Rodkey WG, Webber RJ, McKinney L, Steadman JR. Future directions. Collagen based prosthesis for meniscal regeneration. Clin Orthop 1990;252:129-135.

19. Lie M, Changyoua G, Zhengwei M, Jie Z, Jiacong S. Enhanced biological stability of porous scaffold by using amino acids as novel cross-linking bridges. Biomaterials 2004;25:2997-3004.

20. De Groot JH, De Vrijer R, Pennings AJ, Klompmaker J, Veth RP, Jansen HW. Use of porous polyurethanes for meniscal reconstruction and meniscal prostheses. Biomaterials 1996;17:163-173.

21. Tienen TG, Heijkants RGJC, Buma P, De Groot JH, Pennings AJ, Veth RPH. Tissue ingrowth and degradation of two biodegradable porous polymers with different porosities and pore sizes. Biomaterials 2002;23:1731-1738.

22. Tienen TG, Heijkants RGJC, Buma P, De Groot JH, Pennings AJ, Veth RPH. A porous polymer scaffold for meniscal lesion repair-A study in dogs. Biomaterials 2003;24:2541-2548.

23. Barry JJA, Gidda HS, Scotchford CA, Howdle SM. Porous methacrylate scaffolds: Supercritical fluid fabrication and in vitro chondrocyte response. Biomaterials 2004;25:3559-3568.

24. Parry DAD, Craig AS. Growth and development of collagen fibrils in connective tissue. In Ruggeri A, Motta PM, Editors. Ultrastructure of the connective tissue matrix. Dordrecht: Martinus Nijhoff; 1984.

25. Raspanti M, Ottani V, Ruggeri A. Subfibrillar architecture and functional properties of collagen: a comparative study in rat tendons. J Anat 1990;172:157-164.

26. Peterson W, Tillmann B. Collagenous fibril texture of the human knee joint menisci. Anat Embryol 1998;197:317-324.

27. Birk DE, Trelstad RL. Extracellular compartments in tendon morphogenesis: collagen fibril, bundle and macroaggregate formation. J Cell Biol 1986;103:231-240.

28. Birk DE, Zycband E. Assembly of the tendon extracellular matrix during development. J Anat 1994;184:457-463. 